\title{
Characteristics of Dispersion and Occurrence Rate of Whistlers at Low Latitudes during One Solar Cycle
}

\author{
Masashi Hayakawa, Jinsuke Ohtsu and Akira IwaI \\ The Research Institute of Atmospherics, Nagoya University, Toyokawa, Aichi
}

(Received February 9, 1971)

\begin{abstract}
Electron-density variations in the magnetosphere at a geocentric distance of $\sim 1.50$ earth radii are deduced from whistler dispersion data during one solar cycle from the year 1958 to 1968 . The less sensitivity to the long-term variation of solar activity of the magnetosphere than the ionosphere was found. Also the variation of whistler dispersion at low latitude shows a semi-annual change, which will be discussed in comparison with the ionospheric $\mathrm{f}_{0} \mathrm{~F} 2$ variation. Moreover, the characteristics of occurrence rate of low latitude whistlers are investigated with special reference to the solar-cycle and annual variations. These features on occurrence rate are explained in terms of ionospheric absorption, and duct formation.
\end{abstract}

\section{Introduction}

More than ten years have passed since Iwai and Outsu (1958) commenced the whistler observation at such low latitude as Wakkanai during the IGY period. So the time has come when we are able to investigate the detailed study of variations of dispersion and occurrence rate of whistlers at low latitudes with solar activity during one solar cycle. As one solar cycle we adopt the period from the year 1958 to 1968, and the whistler observation was made at Wakkanai Station till Nov. 15, 1962 and then at Moshiri Station according to the IGY, IGG and IQSY program. The geomagnetic latitudes of Wakkanai and Moshiri are $35.3^{\circ} \mathrm{N}(L=1.50)$ and $34.0^{\circ} \mathrm{N}(L=1.46)$, respectively and the difference between them is only one degree or so. Therefore the data of both stations are treated equally in the study of whistler dispersion.

We have examined whistlers in two time belts of a day, one is $00-04 \mathrm{~h} \mathrm{JST}$ (postmidnight), and the other 15-19h JST (afternoon-evening), in order to study a possible difference in the dispersion variation between night and evening. The data used are selected as follows;

1) Whistlers of extreme dispersions are excluded, i.e., those values larger than $100 \sqrt{\sec }$ and smaller than $20 \sqrt{\mathrm{sec}}$.

2) We excluded whistlers with lower frequency cutoff at around $2 \mathrm{KH}_{z}$ known as tweek cutoff, for it is evident that these whistlers have travelled considerable distances through the earth-ionosphere waveguide as shown by Outsu (1960).

This paper presents additional and more detailed informations to the study worked out by Outsu et al. (1963), Kimpara (1966), and Iwai and Ohtsu (1967). 


\section{Characteristics of Dispersion of Low-latitude Whistlers}

\subsection{Solar-cycle variation}

Figure 1 illustrates the solar-cycle variation of monthly mean solar radio emission for the period beginning from Jan. 1958 and extending to Dec. 1968. We have taken the flux density of solar radio emission of $3750 \mathrm{MH}_{z}$ instead of sunspot number as the measure of solar activity, because the flux intensity of radio emission has more physical

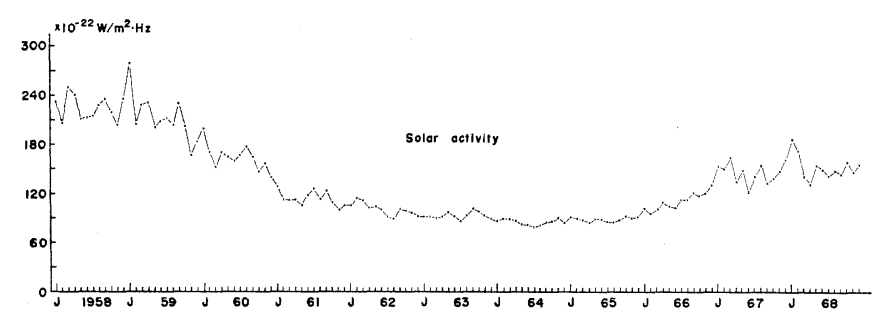

Fig. 1. Solar cycle variation of monthly mean flux intensity of solar radio emission at $3750 \mathrm{MHz}$ observed at Toyokawa. $\mathrm{J}$ means January.

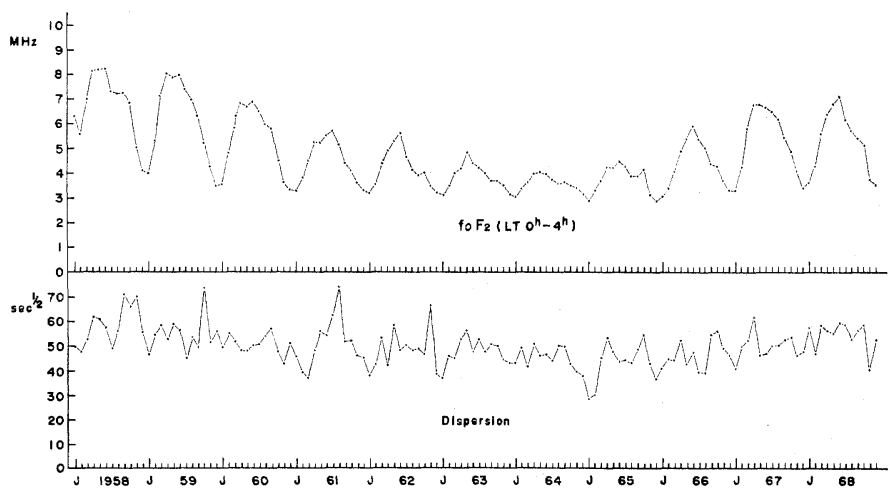

Fig. 2. Solar cycle variation of monthly median $f_{0} F 2$ and whistler dispersion in the time belt $0-4 \mathrm{~h} \mathrm{LT}$ (post-midnight).

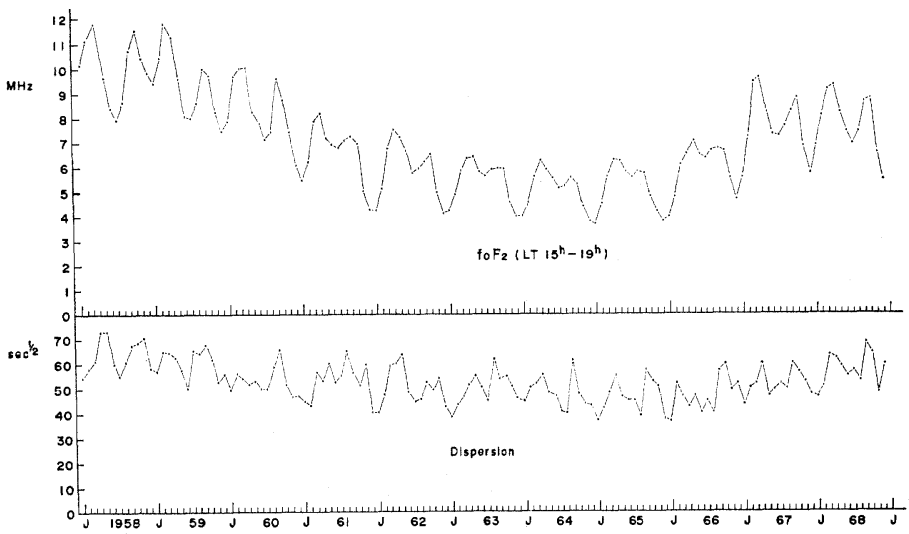

Fig. 3. Solar cycle variation of monthly median $f_{0} F 2$ and whistler dispersion in the time belt 15-19h LT (afternoon-evening). 


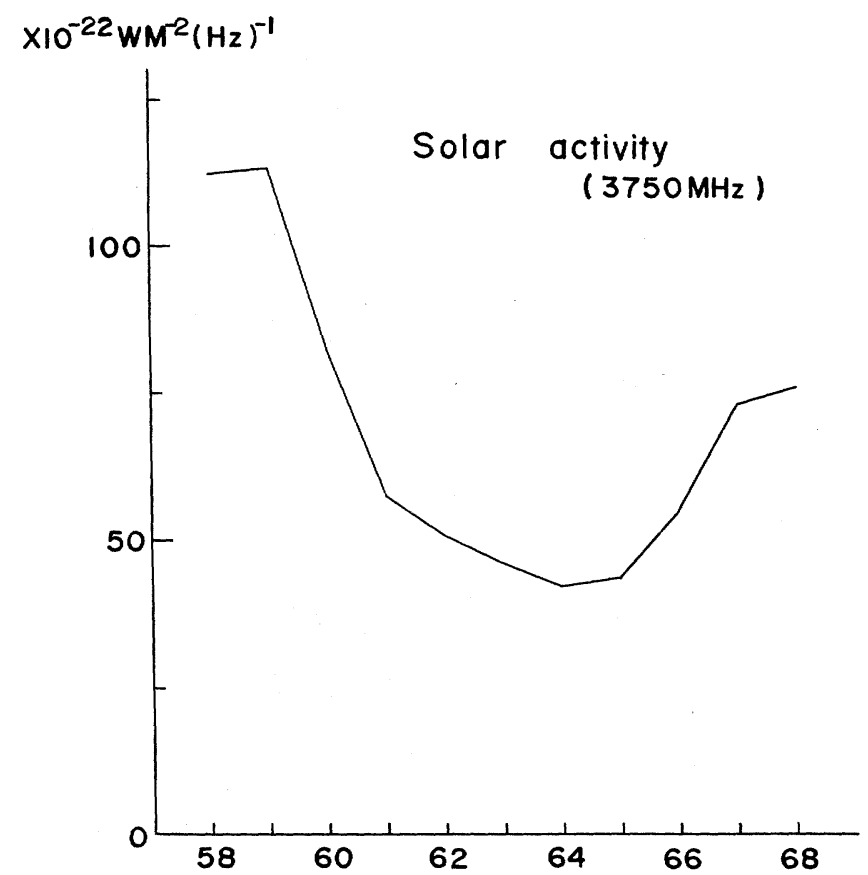

Fig. 4. Secular variation of yearly averaged solar activity.

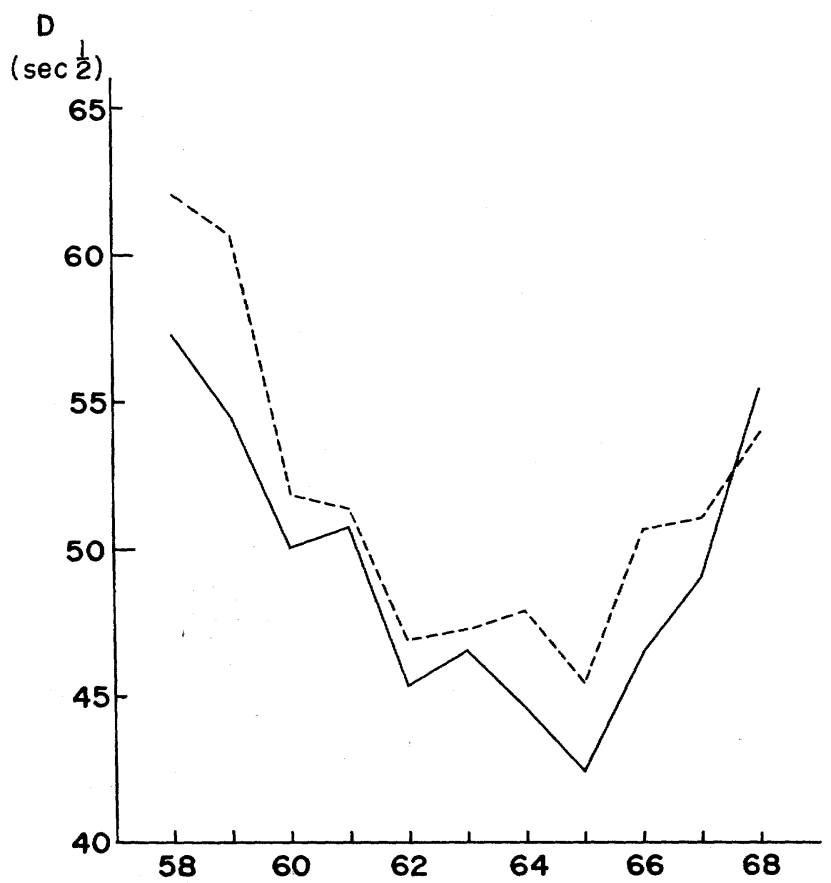

Fig. 5. Secular variation of whistler dispersion. Full line indicates the case of post-midnight whistlers, and the broken line the case of evening whistlers. 


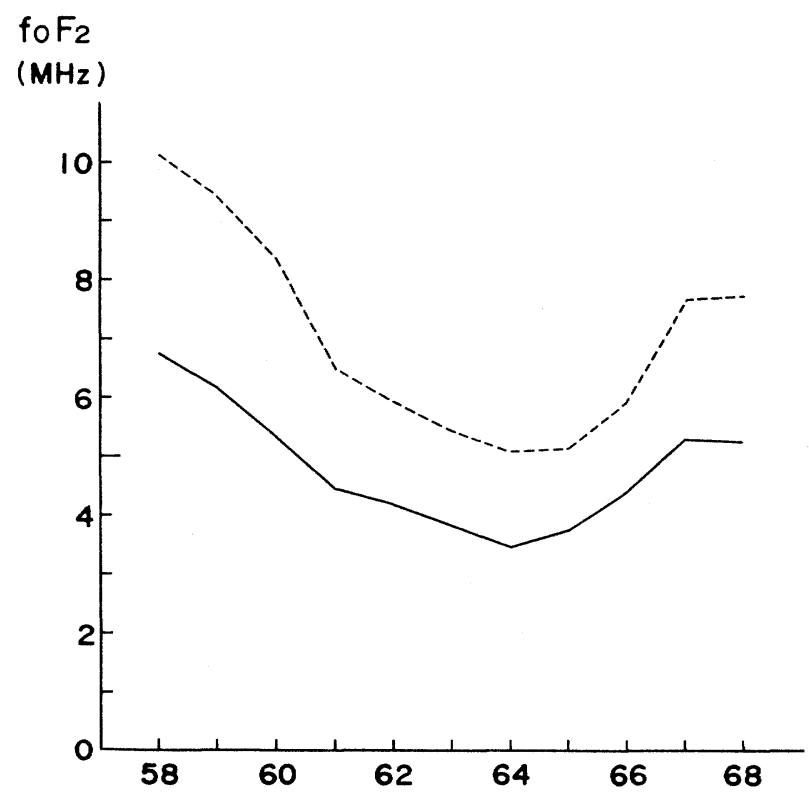

Fig. 6. Secular variation of $f_{0}$ F2. Full line shows the time belt of post-midnight, and the broken line that of evening.

meaning than sunspot number, and also is considered to be associated with solar Xrays as the source of ionization. The data of solar emission were taken from the monthly report of solar radio emission published by Toyokawa Radio Observatory. In Figs. 2 and 3 we have plotted the monthly medians of $f_{0} \mathrm{~F} 2$ observed at Wakkanai Ionospheric Station, the geomagnetic latitude being $35.3^{\circ} \mathrm{N}$, and the monthly averages of whistler dispersion for two time belts. Using these figures, the variation of the 12 month running means of solar activity, whistler dispersion, and $\mathrm{f}_{0} \mathrm{~F} 2$ are shown in Figs. 4, 5 and 6, respectively. In Figs. 5 and 6 the full lines represent the results for the time belt $0-4 \mathrm{~h} /$ $L T$, and the broken lines the case of $15-19 \mathrm{~h}$ LT. First of all, the results of Figures 4 through 6 are discussed. It is apparent from Fig. 4 that the solar activity reached the maximum around the years of 1958 and 1959 and the minimum around 1964 and 1965 . Corresponding to this change of solar activity, the dispersion generally continues to decrease from 1958 to 1965, showing a characteristic minimum, then indicates a considerably rapid enhancement during the range between 1965 and 1968. Throughout this solar cycle, it is clear that the dispersion value of evening whistlers indicated by broken lines is larger than that of mid-night whistlers shown by full lines except the dispersion of 1968. This fact is easily seen from the study of diurnal variation of dispersion worked out by Iwai and Outsu (1958, 1962). These authors found an afternoon maximum and a post-midnight minimum in dispersion using the data at Toyokawa and Wakkanai. Also the similar tendency was observed at high latitudes by Rivault and Corcuff (1960) and Corcuff (1965). The dispersion of the year 1965, being minimum dispersion, is about $74 \%$ and $73.5 \%$ of the value of 1958 for the post-midnight and evening whistlers, respectively. In Fig. 6 the variation of $\mathrm{f}_{0} \mathrm{~F} 2$ shows a minimum at the year of 1964, a little 
different from the results of dispersion. Also it is apparent that the value of $f_{0} F 2$ of the year of 1964 is about 52 and $46.5 \%$ of the 1958 value, for post-midnight and evening whistlers, respectively. Using the dispersion value of the year 1965, the ratios become a little larger than the above values. The above change in $\mathrm{f}_{0} \mathrm{~F} 2$ corresponds to the reduction in electron density by about $75 \%$ for $\mathrm{F} 2$ layer. On the other hand, the dispersion value, especially at low latitudes, includes the considerable amount of contribution from the region around F2 layer. Following the method of Iwai and Outsu (1958), the space in which whistlers propagate along the field line of the latitude of $34^{\circ}$ is divided into two regions, the first of which is the region between $100 \mathrm{~km}$ and $500 \mathrm{~km}$ above the ground (ionospheric region), and the second of which is the region from the altitude $500 \mathrm{~km}$ to the path apex, $\sim 3000 \mathrm{~km}$ (magnetospheric region). The ionospheric contribution to the dispersion in the years 1958 and 1965 is obtained by using the observed $f_{0} \mathrm{~F} 2$ and maximum density height of each year. Then by subtracting the dispersion of ionospheric region from the observed dispersion value, the diminution in electron density by about $35 \%$ is found for the magnetospheric region. These values are nearly consistent with the values inferred by Carpenter (1962) for the period of sunspot maximum. Recently Bouriot et al. (1967) obtained the similar trend with ours by using the whistler data at Poitier. The reduction rate seems to be dependent on the latitude. From these results it is concluded that the magnetosphere is less sensitive than the F2 region of the ionosphere to the long-term variation of solar activity. Such sensitivity will be considered later by means of correlation studies. Judging from Figs. 4 and 6 , the variation of $\mathrm{f}_{0} \mathrm{~F} 2$ seems to have changed in phase with solar activity, though not so clear. The phase of the change in electron density in the magnetosphere is likely to be behind the phase of solar activity, which will be investigated in detail later.

\subsection{Annual variation}

Figure 7 indicates the annual variations of monthly means of dispersions averaged for the period from Jan. 1958 to Dec. 1969. And for comparison, the corresponding variations of $f_{0} F 2$ are shown in Fig. 8. It is apparent that the variations of dispersion show clear semi-annual changes. Larger dispersions occur in March, April, September and October for both post-midnight and evening whistlers. It appears that smaller dispersions take place in May, June, July, December and January for post-midnight whistlers, and in July, August, December and January for evening whistlers. Hence, roughly speaking, it can be said that the dispersion shows maximums in spring and autumn, and minimums in summer and winter, which supports the earlier work of Kimpara (1962 a). It is found that the present results markedly differ from what have been obtained by Helliwell (1961) using data from stations in higher latitudes, such as Stanford, Seattle, Unalaska, and Wellington and by Corcuff (1965) at Poitiers. Their reports showed the annual changes of the same phase in both hemispheres and the minimum dispersion occurred in either June or July, and the maximum in November, December or January, depending on the geomagnetic latitude of the station and year. The minimum dispersion in June or July in Helliwell's report agrees well with our present results, but 


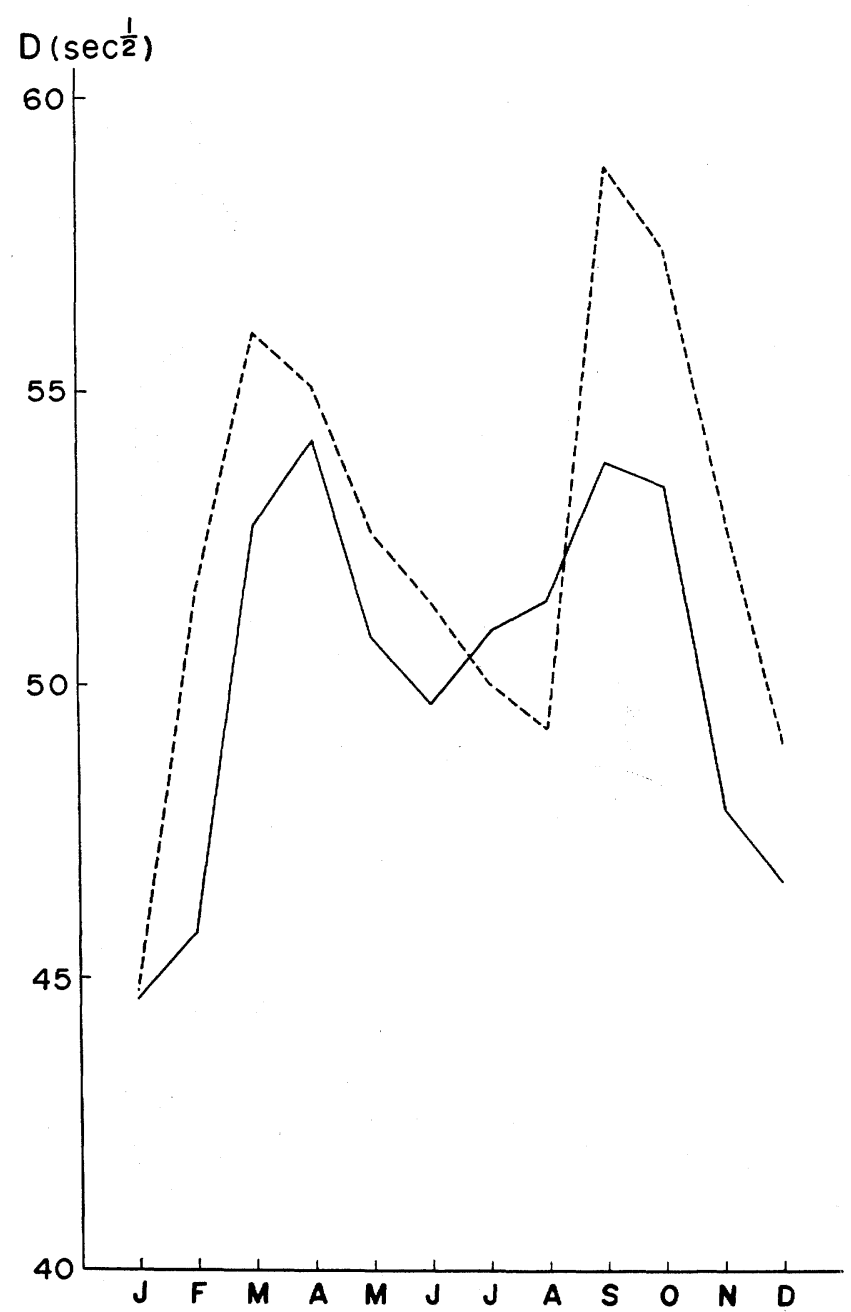

Fig. 7. Annual variation of whistler dispersion.

the maximum in November, December or January differs remarkably from ours. During the latter months, the dispersion falls to the lowest level according to our present analysis. As the whistlers propagate between both hemispheres, the semi-annual variation seems to be more plausible than the annual variation. So the difference in seasonal variation of whistler dispersion between higher and lower latitudes is a problem to be solved by a future study. As an explanation of this problem, Helliwell (1961) suggested that the seasonal variation might be related to the eccentricity of the earth's orbit about the sun, or to the seasonal asymmetry in the relation between the sun-earth line and the geomagnetic equator.

Over the period from 1958 to 1968 the variation of $f_{0} F 2$ shows a great deal of similarity with that of dispersion in the evening. That is, it is apparent that the variation is of a semi-annual type. The larger values of $\mathrm{f}_{0} \mathrm{~F} 2$ appear in spring and autumn, and the smaller values in summer and winter. It is found that the valley in the variation 


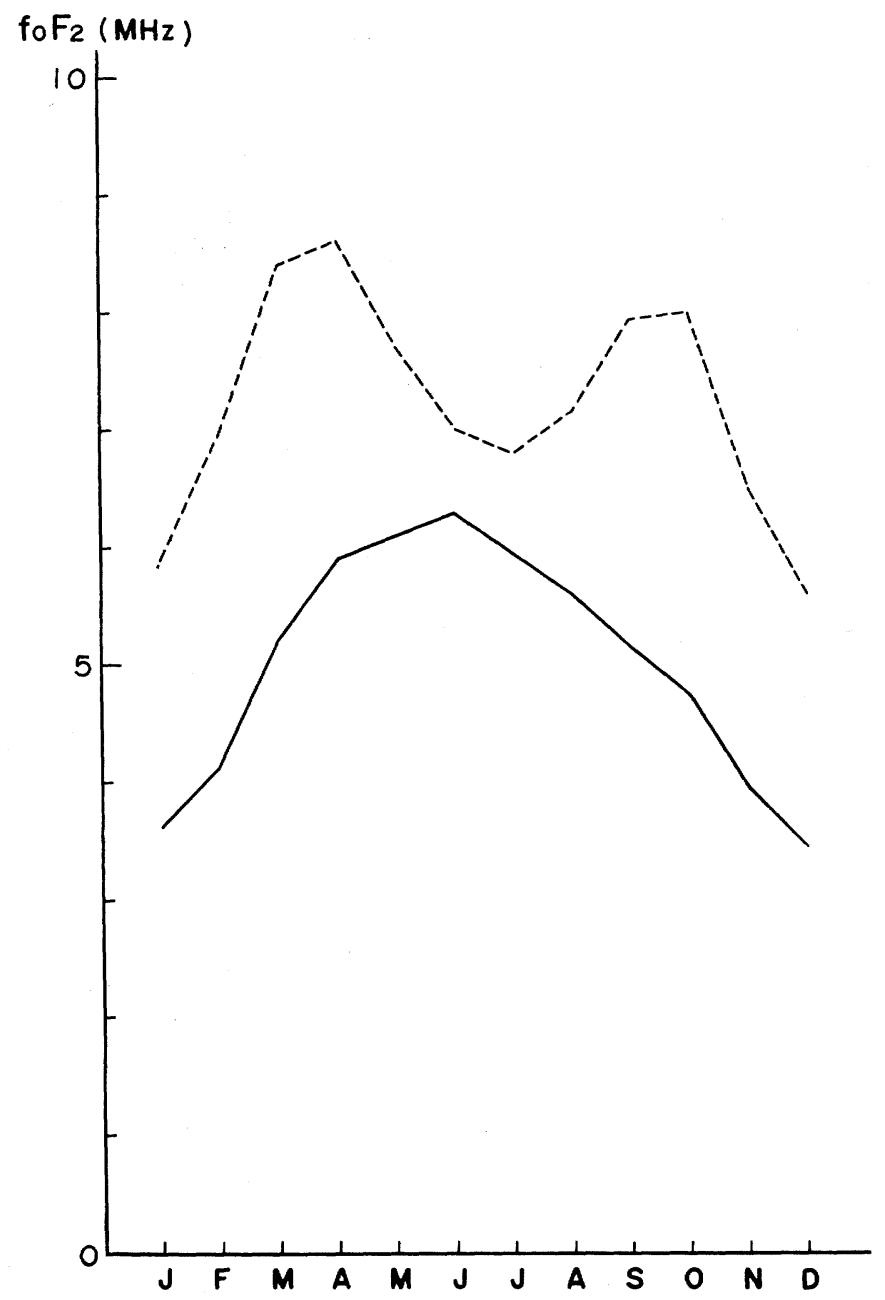

Fig. 8. Annual variation of $f_{0} F 2$.

curve is deeper in winter than in summer, and the peak is higher than in spring than in autumn. On the other hand, one of the most attractive aspects is that the $f_{0} F 2$ variation during the time belt $00-04 \mathrm{~h} L T$ shows a quite different structure from the variation of dispersion of the same time belt. The curve of $f_{0} \mathrm{~F} 2$ is of an annual type in contrast with the dispersion variation of semi-annual type, i.e., the $f_{0} F 2$ has the maximum value in June while the dispersion curve shows a characteristic minimum in the same month. This discrepancy between the seasonal variations of $f_{0} F 2$ and dispersion does not seem to be due to the seasonal scantiness of whistler data in summer. At present the reason of this discrepancy cannot be known.

\subsection{Harmonic analysis of whistler dispersion}

We made harmonic analyses on the variation of Figs. 2 and 3 for the period beginning from Jan. 1958 and extending to Dec. 1968 (total 132 months). The amplitude spectra of dispersion of post-midnight and evening whistlers are plotted in Figs. 9 and 


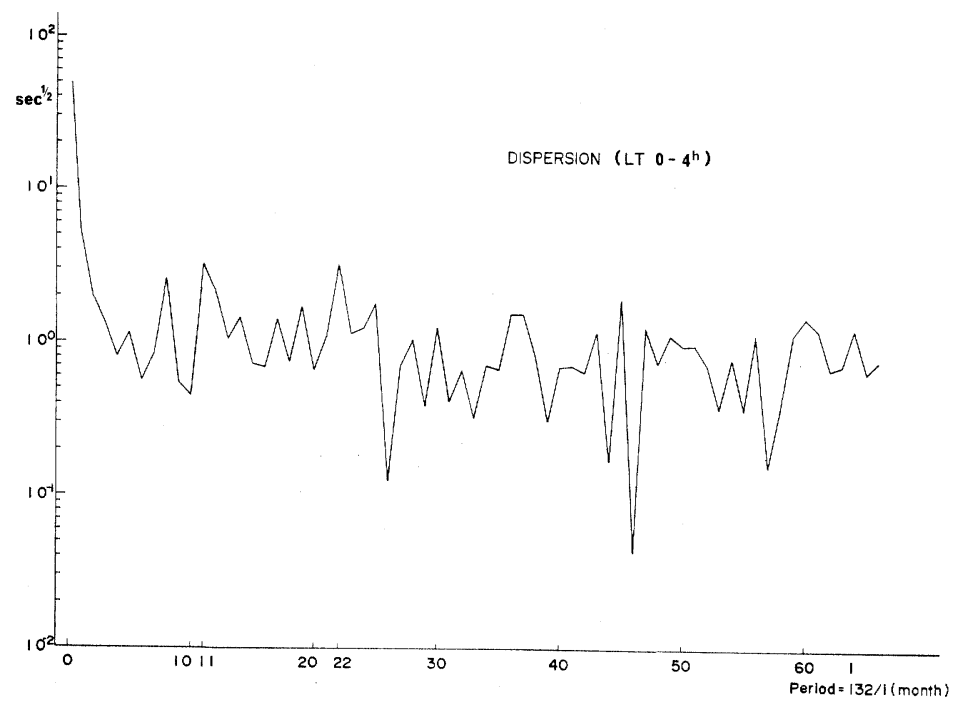

Fig. 9. Amplitude spectrum of whistlers dispersion $(0-4 \mathrm{~h}$ LT). We see the peaks at $i=0,11$, and 22, where $i$ represents the period of variation by the relationship period $($ month $)=132 / i$.

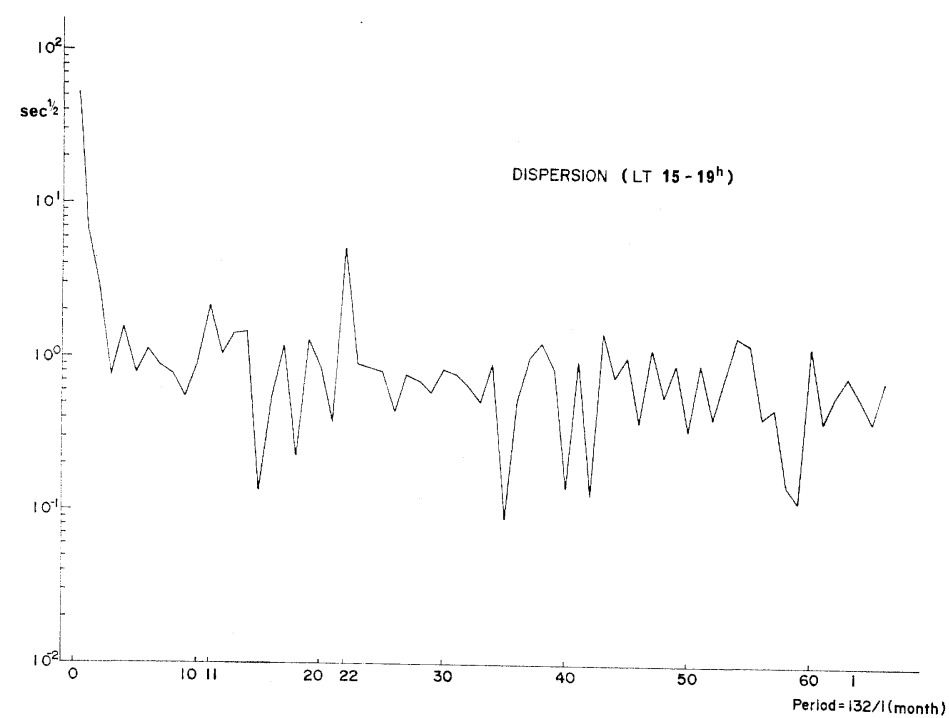

Fig. 10. Amplitude spectrum of whistler dispersion (15-19h LT).

10, respectively. The abscissas indicate implicitly the period in month by the relationship, period $=132 / i$. Figure 9 implies that there appear in the amplitude intensity three characteristic peaks at $i=0,11$ and 22, corresponding to the dc (average), annually varying and semi-annually varying components, respectively. The ratios of the amplitude of an annually varying and a semi-annually varying components to that of dc component is $6.50 \%$ and $6.44 \%$ for post-midnight whistlers. However, judging from Fig. 10 , the amplitude of the semi-annual component is more enhanced than that of postmidnight whistlers in Fig. 9, being a few times of the amplitude of the annual compo- 


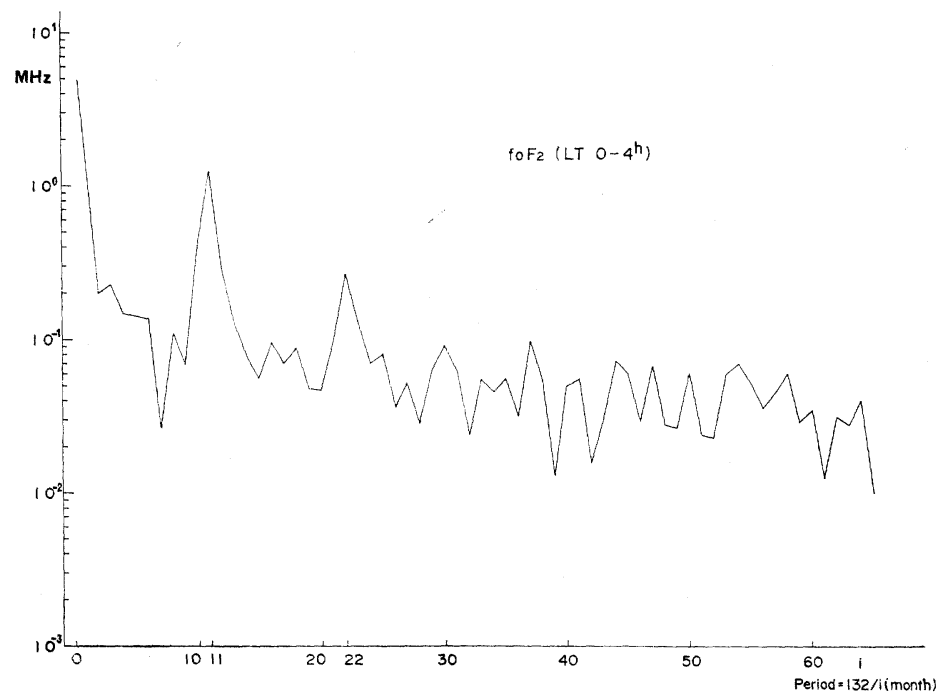

Fig. 11. Amplitude spectrum of $f_{0} \mathrm{~F} 2(0-4 h \mathrm{LT})$.

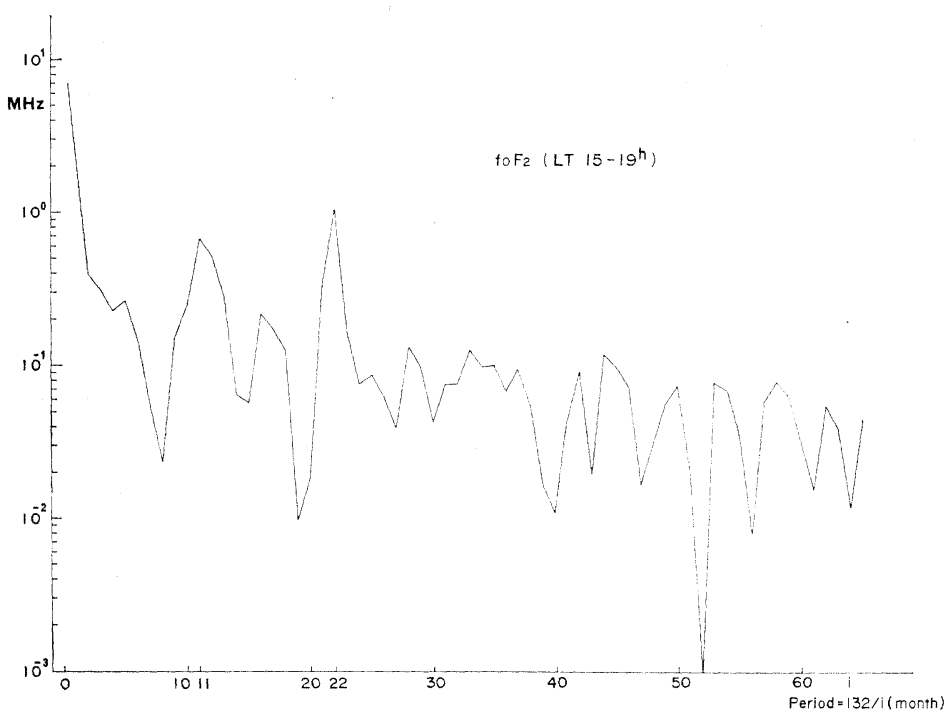

Fig. 12. Amplitude spectrum of $f_{0} F 2$ (15-19h LT).

nent. The amplitude of annually and semi-annually varying components takes the values of $4.16 \%$ and $9.90 \%$ of the dc component. So it may be concluded from the above numerical study that the semi-annual component is more conspicuous for evening whistlers than for post-midnight whistlers. For comparison with dispersion, we plotted the amplitude spectra of $f_{0} \mathrm{~F} 2$ for the two time belts in Figs. 11 and 12 . The percentage ratios of an annual and a semi-annual components to the dc value are $9.52 \%$ and $14.76 \%$ for evening $\mathrm{f}_{0} \mathrm{~F} 2$ and $26.0 \%$ and $5.42 \%$ for post-midnight $\mathrm{f}_{0} \mathrm{~F} 2$. The larger contribution of an annually varying component of $\mathrm{f}_{0} \mathrm{~F} 2$ in the post-midnight may seem 
to result in the variation of one hump type centered at June in Fig. 8, although the phase relation of varying components is important.

\subsection{Correlation of whistler dispersion and $f_{0} F 2$ with solar activity}

Computation of correlation coefficients between dispersion and solar activity, giving the information on time delay of solar effect on magnetospheric electron density variation, shows that there appears a blunt, but significant peak for dispersion 1-3 months later in lag-correlogram between them. The correlation coefficients are represented in Table 1. It seems clear that dispersion of evening whistlers correlates with solar activity more closely than that of post-midnight whistlers. Present results during one solar cycle lend a strong support to the earlier work by Allcock and Morgan (1958), and Kimpara (1962a, 1960a, b). Using the data of middle latitude stations during the year June 1956 to May 1957, Allcock and Morgan obtained a high correlation coefficient of $\sim 0.80$, when the time-delay of dispersion lagged one to two months after the corresponding change in sunspot activity. On the other hand, Kimpara found the same results for low latitude whistlers during the period of high solar activity. However, we must notice here whether there exists the time-lag between the variations of sunspot numbers used by the above workers, and solar radio emission $(3750 \mathrm{MHz}$ ) adopted in the present study. In order to check this point, we analyzed the correlation between them, but in accuracy of a month we did not find out any conspicuous time-delay between them as was stated by Allen (1948). According to him the corona activity closely connected with $3750 \mathrm{MHz}$ radio emission lags 0.87 month behind the sunspot number. Moreover, it is found that such time-lag effect between dispersion and solar activity is

Table 1. Correlation between whistler dispersion $(D)$ and solar activity during the period 1958-1968.

\begin{tabular}{c|c|c|c|c|c|c|c}
\hline Dispersion & $\begin{array}{c}2 \text { months } \\
\text { before }\end{array}$ & $\begin{array}{c}1 \text { month } \\
\text { before }\end{array}$ & $\begin{array}{c}\text { same } \\
\text { month }\end{array}$ & $\begin{array}{c}1 \text { month } \\
\text { later }\end{array}$ & $\begin{array}{c}2 \text { months } \\
\text { later }\end{array}$ & $\begin{array}{c}3 \text { months } \\
\text { later }\end{array}$ & $\begin{array}{c}4 \text { months } \\
\text { later }\end{array}$ \\
\hline $\begin{array}{c}\text { Correlation } \\
\text { coefficient of } D \\
\text { with solar activity } \\
\text { 00-04h LT }\end{array}$ & 0.471 & 0.463 & 0.460 & 0.501 & 0.519 & 0.466 & 0.451 \\
\hline $\begin{array}{c}\text { Correlation } \\
\text { coefficient of } D \\
\text { with solar activity } \\
\text { 15-19h LT }\end{array}$ & 0.570 & 0.577 & 0.578 & 0.636 & 0.625 & 0.576 & 0.562 \\
\hline
\end{tabular}

Table 2. Correlation of $\mathrm{f}_{0} \mathrm{~F} 2$ with solar activity during the period 1958-1968

\begin{tabular}{c|c|c|c|c|c|c|c}
\hline $\mathrm{f}_{0} \mathrm{~F} 2$ & $\begin{array}{c}2 \text { months } \\
\text { before }\end{array}$ & $\begin{array}{c}1 \text { month } \\
\text { before }\end{array}$ & $\begin{array}{c}\text { same } \\
\text { month }\end{array}$ & $\begin{array}{c}1 \text { month } \\
\text { later }\end{array}$ & $\begin{array}{c}2 \text { months } \\
\text { later }\end{array}$ & $\begin{array}{c}3 \text { months } \\
\text { later }\end{array}$ & $\begin{array}{c}4 \text { months } \\
\text { later }\end{array}$ \\
\hline $\begin{array}{c}\text { Correlation } \\
\text { coefficient of } \mathrm{f}_{0} \mathrm{~F} 2 \\
\text { with solar activity } \\
\text { 00-04h LT }\end{array}$ & 0.664 & 0.639 & 0.647 & 0.664 & 0.681 & 0.682 & 0.656 \\
\hline $\begin{array}{c}\text { Correlation } \\
\text { coefficient of f F2 } \\
\text { with solar activity } \\
\text { 15-19h LT }\end{array}$ & 0.798 & 0.792 & 0.812 & 0.840 & 0.846 & 0.822 & 0.779 \\
\hline
\end{tabular}


more pronounced during the high solar activity than during the low solar activity. The same, though less clear, tendency was also found in the correlation between $\mathrm{f}_{0} \mathrm{~F} 2$ and solar activity, as shown in Table 2. Comparison of Tables 1 and 2 shows us numerically the less sensitivity of magnetosphere to long-term variation of solar activity than the ionosphere, mentioned in Sec. 2. 1.

\section{Characteristics of Occurrence Rate of Low-latitude Whistlers}

\subsection{Solar-cycle variation}

Figure 13a shows the solar-cycle variation of total whistler occurrence number in a year counted on the routine base observation (two-minutes every half an hour). We must remark that the total number in the year of 1962 contains the occurrence rate at Wakkanai till 15 Nov. and that at Moshiri thereafter. The occurrence number at Moshiri in December 1962 amounts to the high value of $1.85 \times 10^{4}$, so the occurrence number of the year of 1962 takes greater value than that of 1961 . Consequently the value at the year 1962 is less reliable. The variation curve since the year 1963 in Fig. 13a shows the solar-cycle variation at Moshiri station. In the following we discuss the results for Wakkanai and Moshiri Stations separately. From the comparison of Figs. 4 and $13 \mathrm{a}$, it is generally distinct that the occurrence rate at Wakkanai increases in accordance with the decrease of solar activity with an exception of small depletion around the year 1961. While at Moshiri the occurrence rate is found to take a characteristic great value at the year 1963, then decrease sharply and reach a minimum at 1965 . The difference in absolute values of occurrence rate at Wakkanai and Moshiri may be due to the differenct noise levels and the different thunderstorm activities near the conjugate points of the two stations.

In Fig. 13b we present the curve of the sum of monthly occurrence rate during the five winter months (Nov., Dec., Jan., Feb., and Mar.) of higher whistler activity, which will be justified in the next section. Also the variation of the sum of monthly mean of solar radio emission during the same months is plotted for comparison. When plotting Fig. 13b, we excluded the year during which the observation site is changed from Wakkanai to Moshiri. Clearly seen is the fact that the occurrence rate at Wakkanai increases from the year 1958 to 1961 as the solar activity decreases. Using the whistler data during the above 4 years, Kimpara (1962 b) found a surprisingly high negative correlation coefficient such as over $-90 \%$. However, the occurrence rate of the year 1962 is smaller than that of 1961 , in spite of decreased solar activity. The general trend of inverse correlation between occurrence rate and solar activity is apparently recognized. According to our correlation study, the correlation coefficient at Wakkanai between them is found to be $-32 \%$. On the other hand, the occurrence rate at Moshiri decreases generally with considerable fluctuations, whereas the solar activity increases year by year. The correlation coefficient at Moshiri is $-43 \%$. From these results at Wakkanai and Moshiri, we can firmly conclude that at lower geomagnetic latitudes, the occurrence rate of whistlers is inversely correlated with solar activity. 


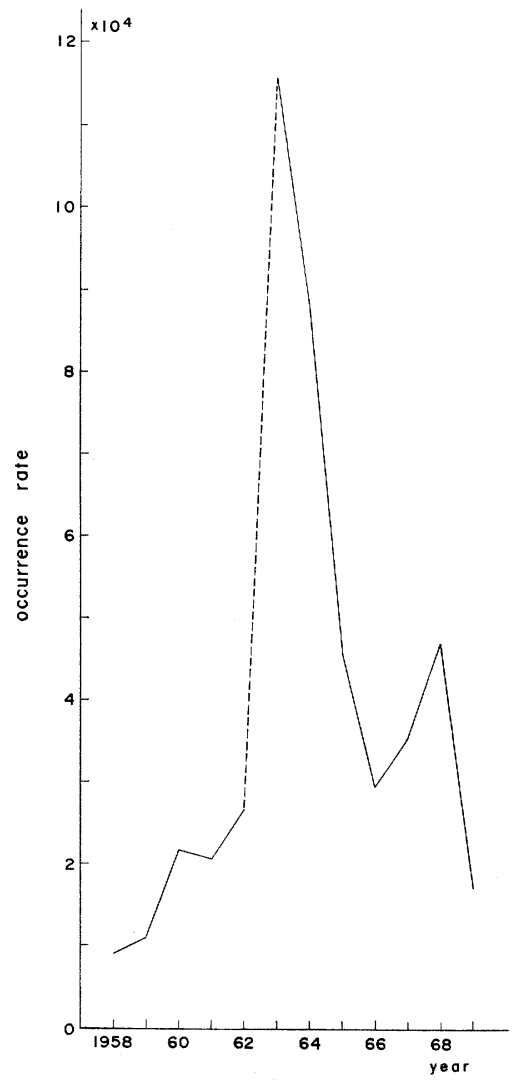

Fig. 13a. Secular variation of yearly total occurrence rate.

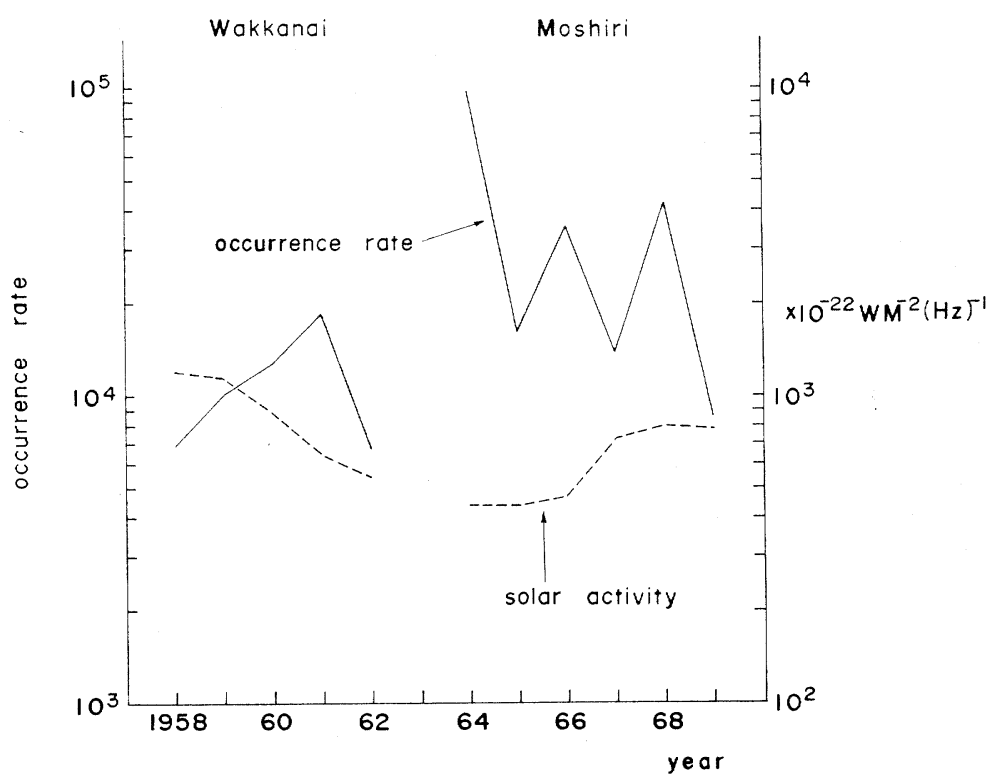

Fig. 13b. Secual variation of total occurrence rate in wintertime five months. For comparison, the variation of solar activity is also plotted. 


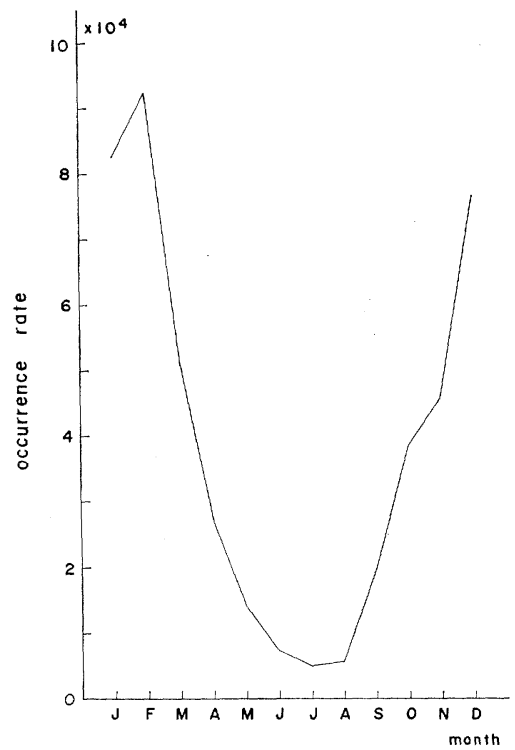

Fig. 14. Annual variation of occurrence rate averaged over one solar cycle,

\subsection{Annual variation}

Figure 14 illustrates the seasonal variation of whistler activity averaged over the period from 1958 to 1968. From this figure it is clearly found that the variation of occurrence shows a maximum in winter and a minimum in summer. Larger occurrence rates appear in December, January and February, and also smaller whistler activity is found in June, July and August. The ratio of maximum occurrence rate in February to the minimum value in July attains to the value of 18.5. The present facts give a support to the work using the data during the high solar activity by Kimpara (1960a, b), Outsu et al. (1963), and Kimpara (1966). According to Helliwell (1960) the seasonal variations of whistler activity are quite complicated, i.e., stations at geomagnetic latitudes lower than roughly $52^{\circ}$ and greater than $62^{\circ}$ show a wintertime maximums in occurrence, whereas stations between $52^{\circ}$ and $62^{\circ}$ latitudes show a summertime maximum. Laaspere et al. (1963), and our present work support the Helliwell's summary. These facts may be considered in terms of duct formation, and ionospheric absorption etc.

\section{Discussions}

It is well known that whistler is a very useful tool in obtaining information on the physical environment of the earth along the whistler path. However, the most intrinsic questions in whistler dispersion are the ambiguity of path latitude of whistlers, especially at low latitudes, and what is the main contribution to the dispersion value. The first disadvantage can be overcome at high latitudes by making use of nose whistlers. That is, we can easily estimate the apex of whistler path from nose frequencies.

But at low latitudes the nose frequency amounts to $55-70 \mathrm{kHz}$ at Moshiri (Ohtsu and Iwai, 1967), so such nose frequencies don't fall into the frequency range of routine observation. Moreover low-latitude nose whistlers cannot be detected frequently ow- 
ing to the fact that the absorption loss of whistler modes increases with increasing frequency and with decreasing latitude (Helliwell, 1965 and Somayajulu and Tantry, 1967). Although we cannot use nose-whistler data, the dispersion data presented in this paper is thought to reflect the magnetospheric state associated with the field line of the latitude $\sim 35^{\circ}$ (so $L \sim 1.50$ ) to a considerable accuracy on the following ground. It seems reasonable that the propagation of low-latitude whistlers is confined in field-aligned ducts as proposed by Smith (1961). Rocket observation by Hayakawa et al. (1970) showed that if there don't exist such ducts, whistlers cannot penetrate through the F2 region down to the ground due to the hard transmission condition. Ducted whistlers observed at Wakkanai and Moshiri Stations, of course, include those whose path endpoint latitude is smaller or larger than the station latitude. Judging from the emerging wave normal direction from the ionosphere, it follows that whistlers propagate through the earthionosphere waveguide more easily from lower to higher latitudes. Then the number of whistlers of lower path latitude is numerous, whereas the tendency for higher latitude whistlers is vice versa. On the other hand, the lower the path latitude becomes, the smaller the dispersion value becomes. So it seems that the dispersion value at Wakkanai and Moshiri affords us a means of probing the regions along the field line of $L \sim 1.50$, or a little smaller $L$ values. The next problem is whether the dispersion is determined by only the magnetospheric electron density, or not. The dispersion, $D$, is expressed as follows, since the $Q L$ approximation is valid in the region we are concerned with,

$$
D=\frac{1}{2 c} \int_{\mathrm{path}} \frac{f_{0}}{\sqrt{f_{H}}} d s
$$

where $f_{0}$ and $f_{H}$ are plasma and electron gyro-frequencies, and $s$ the path length. And the integration is carried out along the path. From the notation of $D$, it is found that the dispersion may be resulted from the electron density, magnetic field intensity and path length. The effect of the variation in the path endpoint latitude is so small that it is neglected in this analysis.

First we consider the solar-cycle variation in Sec. 2.1. It is found as a general tendency that the whistler dispersion decreases with diminishing solar activity, and it is enhanced during high solar activity. According to Bouriot et al. (1967), the magnetospheric electron density at $L=2.25$ during low solar activity is reduced by about $25 \%$ compared with that during high solar activity. In low latitude $(\mathrm{L} \sim 1.50)$, the corresponding reduction rate is about $40 \%$, whereas the rate of $\mathrm{F} 2$ region of the ionosphere is about $75 \%$. Also the less sensitivity to the long-term variation of solar activity of the magnetosphere than the ionosphere was numerically made clear in the correlation studies. It is considered recently that the exospheric electrons are originated from the terrestrial ionosphere. The lower ionosphere is first ionized by the solar X-ray and UV-radiation, then the ionized electrons diffuse upwards to the exosphere. So the less sensitivity to the variation of solar activity of the magnetosphere than the ionosphere seems to be a reasonable fact. The computation of correlation between whistler dispersion and solar activity showed that there existed a positive correlation between them, the dispersion 
lagging about a few months behind the solar activity. The time-lag effect is apparent to be more pronounced during high solar activity than during low activity. Such characteristics as mentioned above hold generally, though a little different, for two time belts, i.e., evening and post-midnight.

Next we pay particular attention to the annual variation of whistler dispersion. The variation of dispersion at low latitude shows apparently semi-annual changes. It can be said that the dispersion shows maximums in spring and autumn, and minimums in summer and winter. The annual variation in magnetospheric electron density at high latitude (Carpenter, 1962, and Saito, 1964) is quite different from the results at low latitudes. Now we must consider the fact that the annual variation of dispersion cannot be seasonal, but non-seasonal, since the whistler dispersion is resulted from the propagation between both hemispheres. According to the works of Yonezawa and Arima (1959) and Yonezawa (1967), they divided the annual variation at a station of electron density of F2 layer of the ionosphere into the following four components, i.e., the annual average, the components of the seasonal, non-seasonal annual variations, and semiannual variations. Therefore unless we subtract the seasonal variation in the electron density of F2 layer in their study, the accurate comparison between the ionospheric and magnetospheric electron density variation cannot be made. In order to compare with the results of Yonezawa, the dispersion values are transformed into the variation of exospheric density along the field line $L \sim 1.50$. According to harmonic analyses of such density variation, the annually and semi-annually varying components take the values of 13.60 and $13.74 \%$ of the average at post-midnight, while the corresponding ratios are 8.08 and $19.22 \%$ in the evening. The amplitude of varying components (non-seasonal annual and semi-annual components) in the lower exospheric electron density deduced from our study is about $28 \%$ of the average value. Yonezawa and Arima (1959) showed that the varying components in density in F2 layer is about $35 \%$ of the average when we take the mean value of the cases of sunspot number 0 and 100 . Since the ionospheric contribution is included in the dispersion, it is expected that the percentage of varying components is less than $28 \%$ for the magnetosphere, though we cannot get its exact value. From the comparison of the F2 layer and lower exospheric density variation with relatively small amplitude $(10 \%$ at most) of varying components in the magnetosphere inferred from Carpenter's paper, it may be confident that such varying components diminish in amplitude when diffusing into the upper exosphere. The most distinguished difference between Yonezawa's work and ours is that the semi-annually varying component is more enhanced in amplitude in the lower exosphere than in the ionosphere. Also Paetzold (1964) found such kind of annual and semi-annual changes in upper atmospheric temperature, which may be an effective measure of thermal diffusion. The non-seasonal annual variation shows a maximum in Dec. or Jan., while the semi-annual one in April and October at noon, in May, or June and Nov., or Dec. at midnight. So the phase of semi-annual variation seems to be highly variable. To our surprise, the superposition of non-seasonal annual, and semi-annual components 
plus the annual average using the equatorial $\mathrm{f}_{0} \mathrm{~F} 2$ data indicates an astonishingly good similarity with Helliwell's (1965) annual variation of whistler dispersion at $L \sim 3$. From above-mentioned discussions, the highly variable semi-annual components, taking both amplitude and phase into consideration, may have a serious effect in the annual variation curve of exospheric electron density, as well as the non-seasonal annual components.

As for the consideration of occurrence frequency, the annual variation of occurrence rate is understood clearly from the seasonal variation of thunderstorm activity near the conjugate points. Next the inverse correlation between the occurrence rate and solar activity must be explained in terms of thunderstorm activity and propagation characteristics. The solar-cycle variation of thunderstorm activity is considered to be so little (Takagi, 1970) that the solar-cycle variation of occurrence rate in Figs. 13a and $13 \mathrm{~b}$ is not attributed to it alone. Although this effect may be included in the occurrence frequency variation, the main features in occurrence rate seem to be resulted from the transmission properties of whistlers. The most important factors controlling the occurrence rate are as follows. The first is the absorption loss in passing through the ionosphere into the exosphere. The second is the propagation loss of whistlers in the magnetosphere, and the third the ionospheric absorption of down-going whistlers. According to the theoretical work of Somayajulu and Tantry (1967), the collisional absorption of $D$ and $E$ layers during sunspot maximum is a little greater than that during sunspot minimum at daytime. Since these authors did not show us the numerical values of absorption for nighttime of high whistler activity, we cannot determine the difference in nighttime absorption during sunspot maxima and minima. Experimentally, Austin (1927) measured the intensity of atmospherics, and found that the intensity of atmospherics varies inversely with solar activity. Considering together the results of Austin and our present study, it can be concluded that the ionospheric absorption of VLF waves increases with the enhancement of solar activity, and decreases with the depletion of solar activity. Once having penetrated through the ionosphere, the whistlers suffer from propagation loss in travelling in the magnetosphere. However, if there exist fieldaligned ducts for trapping of whistlers, such loss may become considerably small. It seems reasonable that the ducts can be more easily formed during high solar activity than during low solar activity, though the formation mechanism of whistler ducts remains quite unknown. The most attractive point of the existence of ducts is not only lessening the energy divergence of whistlers, but also loosening the hard transmission condition of down-going whistlers for us to observe them on the ground. The downgoing whistlers satisfied the transmission condition must suffer from the absorption once more. In this case the same discussion can hold good as the case of upgoing waves. From above discussions it is found clear that during depleted solar activity, the ionospheric absorption may be small, whereas the duct formation rate is expected to be high. Therefore in explaining the inverse correlation of occurrence rate with solar activity in Figs. 13a and b, it is found that the absorption effect may prevail over the influence of duct formation, and the duct existence is only the necessary condition. 


\section{Acknowledgement}

The authors wish to express their sincere thanks to Prof. H. Tanaka, Y. Tanaka, M. Nakano and other colleagues of the Res. Inst. Atmosph. for their helpfull discussion and criticism of the manuscript. Also appreciable thanks are due to Miss K. Kawakatsu in preparing the manuscript.

\section{References}

Allcock, G. Mck., and M.G. Morgan, Solar activity and whistler dispersion, J. Geophys. Res., 63, 573-576, 1958.

Allen, C.W., Critical frequencies, sunspots, and the sun's ultra-violet radiation, Terr. Mag., 53, 433-448, 1948.

Austin, L.W., Proc. I.R.E., 15, 825-836, 1927.

Bouriot, M., M. Tixier, and Y. Corcuff, Etude de l'ionisation magnétosphérique entre 1, 9 et 2, 6 rayons géocentriques au moyen des sifflements radioélectriques recus à Poitiers au cours d'un cycle solaire, Ann. Geophys., 23, 527-534, 1967.

Carpenter, D.L., Electron-density variations in the magnetosphere deduced from whistler data, J. Geophys. Res., 67, 3345-3360, 1962.

Corcuff, Y., Étude de la magnétosphère au moyen des sifflements radioélectriques, Thèse de Doctorat d'Etat, Poitiers, juin 1965.

Hayakawa, M., J. Ohtsu, and A. Iwai, Rocket observation of very low frequency radio waves in the ionosphere, Rep. Ionosph. Space Res. Japan, 24, 13-23, 1970.

Helliwell, R.A., Summary of research on whistlers and related phenomena, J. Res. NBS, 64D, 642-644, 1960.

Helliwell, R.A., Exospheric electron density variations deduced from whistler data, Ann. Géophys., 17, 7681, 1961.

Helliwell, R.A., Whistlers and related phenomena, Stanford Univ. Press, 1965.

Iwai, A., and J. Outsu, On the characteristic phenomena for short whistlers observed at Toyokawa in winter, Proc. Res. Inst. Atmospherics, Nagoya Univ., 5, 53-63, 1958.

Iwai, A., and J. Outsu, Observed method for whistlers and its results, J. Inst. Elect. Comm. Engr. Japan, 45, 556-563, 1962.

Iwai, A., and J. Ohtsu, Long-term variation of whistler dispersion, Proc. Res. Inst. Atmospherics, Nagoya Univ., 14, 51-55, 1967.

Kimpara, A., On some remarkable characteristics of whistling atmospherics, Proc. Res. Inst. Atmospherics, Nagoya Univ., 7, 40-57, 1960a.

Kimpara, A., On some remarkable characteristics of whistling atmospherics, Rep. Ionosph. Space Res. Japan, 14, 160-179, 1960 b.

Kimpara, A., Some characteristics of the dispersion of whistlers, Proc. Res. Inst. Atmospherics, Nagoya Univ., 9, 5-17, 1962a.

Kimpara, A., Occurrence rate of whistlers and solar activity, Proc. Res. Inst. Atmospherics, Nagoya Univ., 9, 43-44, $1962 \mathrm{~b}$.

Kimpara, A., Charactéristiques des sifflements radioélectriques aux basses latitudes pendant I'AGI et les AISC, Ann. Géophys., 23, 13-16, 1966.

Laaspere, T., M.G. Morgan, and W.C. Johnson, Some results of five years of whistler observations from Labrador to Antarctica, Proc. IEEE, 51, 554-568, 1963.

Ohtsu, J., and A. Iwai, Low-latitude nose whistlers, Proc. Res. Inst. Atmospherics, Nagoya Univ., 14, 15-22, 1967.

Outsu, J., Numerical study of tweeks based on waveguide mode theory, Proc. Res. Inst. Atmospherics, 
Nagoya Univ., 7, 58-71, 1960.

Outsu, J., A. Iwai, and Y. Tanaka, Annual variations of whistler occurrence rate in middle and low latitudes since July, 1957, Bull. Res. Inst. Atmospherics, Nagoya Univ., 13, 11-24, 1963.

Paetzold, H.K., New results about the annual and semi-annual variation of the upper terrestrial atmosphere, Space Research 4, North-Holland Pub. Comp., 271-278, 1964.

Rivault, R., and Y. Corcuff, Recherche du point conjugué magnétique de Poitiers- variation nocturne de la dispersion des sifflements, Ann. Géophys., 16, 530-554, 1960.

Saito, T., Annual and semi-annual variations in the exospheric plasma densities deduced from pc4 and pc5, Rep. Ionosph. RSpace Res. Japan, 18, 197-212, 1964.

Smith, R.L., Propagation characteristics of whistlers trapped in field-aligned columns of enhanced ionization, J. Geophys. Res., 66, 3699-3708, 1961.

Somayajulu, V.V., and B.A.P. Tantry, Absorption of very low frequency waves in the whistler mode propagation at low latitudes, J. Geomag. Geoelect., 19, 81-89, 1967.

Takagi, M., private communication, 1970.

Yonezawa, T., and Y. Arima, On the seasonal and non-seasonal annual variations and the semi-annual variations in the noon and midnight electron densities of the $\mathrm{F} 2$ layer in middle latitude, J. Radio Res. Labs., 6, 293-310, 1959.

Yonezawa, T., On the seasonal, non-seasonal and semi-annual variations in the peak electron density of the F2 layer at noon in the equatorial zone, J. Radio Res. Labs., 14, 1-25, 1967. 